\title{
OPTIMALISASI JARINGAN WAN BERBASIS MIKROTIK (STUDI KASUS : ROBOTIC LABORATORY BOGOR)
}

\author{
${ }^{1}$ Ilham Nur Leksono, ${ }^{2}$ Tommi Alfian Armawan Sandi \\ ${ }^{1,2}$ Teknologi Komputer, Fakultas Teknologi Informasi, \\ Universitas Bina Sarana Informatika \\ Email: ${ }^{1}$ ilham.inl@bsi.ac.id, ${ }^{2}$ tommi.taf@bsi.ac.id
}

\begin{abstract}
Abstrak
Jaringan komputer adalah dua atau lebih komputer otonom yang saling terhubung baik fisik maupun wireless dan menggunakan aturan-aturan atau protokol melalui media transmisi sehingga dapat saling bertukar informasi serta sumber daya. Pada sebuah teknologi jaringan komputer diperlukan perangkat yang bertugas mengatur atau memanajemen jaringan yang ada. Perangkat tersebut adalah Router. Saat ini pada Kantor Robotic Laboratory Bogor, jaringan komputer yang ada masih belum terstruktur dan belum ada administrasi jaringan, dimana jaringan yang ada hanya berasal langsung dari ISP yang ada dan disebar langsung kepada klien. Sehingga belum optimalnya penggunaan serta fitur yang ada dalam jaringan komputer tersebut. Penelitian ini bertujuan mengoptimalkan jaringan WAN berbasis MikroTik, dimana sebuah perangkat router yang didalamnya sudah tertanam sistem operasi jaringan. Dari hasil penelitian dan analisa bahwa sistem jaringan komputer yang ada pada Robotic Laboratory Bogor menggunakan topologi star dengan internet yang bersumber dari ISP. Optimalisasi jaringan komputer menggunakan MikroTik router dengan mengaktifkan DHCP Server, manajemen bandwidth, hotspot, firewall, wireless dan web proxy hasil nya jaringan komputer yang ada pada Robotic Laboratory Bogor menjadi lebih optimal dan maksimal dalam penggunaan serta pengawasannya.
\end{abstract}

Kata Kunci: Jaringan, MikroTik, Optimalisasi, RouterBoard.

\begin{abstract}
A computer network is two or more autonomous computers that are connected both physically and wirelessly and use rules or protocols through the transmission media so that they can exchange information and resources. In a computer network technology needed a device that is in charge of managing or managing an existing network. The device is a Router. At present at the Bogor Robotic Laboratory Office, the existing computer network is still not structured and there is no network administration, where the existing network only comes directly from the existing ISP and is distributed directly to clients. So that the use and features that are not yet optimal in the computer network. This study aims to optimize the microTik-based WAN network, where a router device that has a network operating system embedded in it. From the results of research and analysis that the existing computer network systems at the Bogor Robotic Laboratory use a star topology with the internet sourced from ISPs. Optimizing computer networks using a proxy router by activating DHCP Server, bandwidth management, hotspots, firewalls, wireless and web proxies, the results of existing computer networks in Bogor Robotic Laboratory become more optimal and maximum in their use and supervision.
\end{abstract}

Keywords: Network, MikroTik, Optimalisazion, RouterBoard. 


\section{PENDAHULUAN}

Perkembangan teknologi jaringan komputer yang semakin pesat membuatnya menjadi faktor yang sangat penting bagi banyak individu serta perusahaan maupun instansi. Pada sebuah perusahaan ataupun instansi dimana karyawannya bekerja menggunakan komputer sebagai alat untuk membantu pekerjaan mereka, maka jaringan komputer secara perlahan menjadi salah satu kebutuhan yang wajib di sediakan. [1] Jaringan komputer adalah sebuah sustem yang terdiri dari komputer-komputer yang dirancang untuk dapat berbagi resource (Printer CPU), berkomunikasi (dalam bentuk surel, pesan instan) dan dapat mengakses informasi secara bersama-sama.

Pembangunan sebuah jaringan komputer tidak luput dari faktor efektifitas dan efisiensi dari jaringan yang akan di instal. Pemilihan topologi, perangkat jaringan, media transmisi, dan alat pendukung lainnya dan pengelolaan dimasa yang akan datang juga harus di pertimbangkan denan sangat matang agar dapat meminimalisir masalah yang mungkin akan muncul. [2] Perusahaan akan berkembang dengan baik jika ditunjang oleh perangkat komputer dan jaringan yang memadai, namun penggunaannya harus diatur agar dapat menunjang kinerja perusahaan.

QoS merupakan sebuah sistem arsitektur end to end dan bukan merupakan sebuah feature yang dimiliki oleh jaringan. Quality of Service suatu network merujuk ke tingkat kecepatan dan keandalan penyampaian berbagai jenis beban data di dalam suatu komunikasi. Aplikasi yang berbeda memerlukan suatu persyaratan QoS tertentu agar selama proses pentransmisian tidak terlalu banyak paket yang hilang, layanan real-time yang baik, delay yang rendah dan alokasi bandwidth yang baik [3].

Teknologi Wireless Network sudah lama ditemukan dan seiring waktu juga mengalami perkembangan, Namun sifat teknologi ini menggantungkan diri pada infrastruktur jaringan yang ada. Hal ini bisa menjadi kelemahan tersendiri saat kondisi infrastruktur jaringan sedang mengalami gangguan, karena setiap komunikasi yang melewati infrastruktur jaringan tersebut tidak akan sampai pada tujuan [4]. Kebijakan atau policy dari sebuah lembaga atau kampus yang berhubungan dengan penggunaan jaringan di terjemahkan dengan membuat konfigurasi firewall pada router MikroTik dibuat dengan model firewall bertingkat, artinya dibuka koneksi dengan beberapa port, protokol yang diijinkan selain itu di drop [5].

Faktor keamanan pada teknologi informasi saat ini sangatlah penting, dikarenakan pada zaman yang semakin berkembang data merupakan segalanya. Ancaman serangan terhadap jaringan dan server juga ikut berkembang, maka diperlukan adanya sebuah penanganan terhadap ancaman yang dapat memantau dan menganalisis ancaman serangan yang sedang berlangsung pada server hal ini dapat menggunakan proxy[6].

Saat ini tidak sedikit perusahaan maupun instansi yang memerlukan konektivitas internet yang terstruktur di kantor mereka hal ini dikarenakan internet yang memang sudah menjadi salah satu kebutuhan penunjang dalam sebuah pekerjaan[7]. Pengelolaan sumber daya jaringan komputer tentu harus diperhatikan, agar konektivitas jaringan internet dapat berjalan dengan lacar dan minim kendala. Seperti halnya pada Robotic Laboratory Bogor, jaringan komputer menjadi sebuah kebutuhan penting agar dapat berkomunikasi antar setiap bagian yang ada pada kantor Robotic Laboratory Bogor. Penelitian ini bertujuan untuk mengelola berupa DHCP Server, hotspot, bandwidth, wireless, firewall serta web proxy juga perlu dilakukan mengingat banyaknya pengguna yang terhubung 
Jusikom : Jurnal Sistem Komputer Musirawas Vol 04 No 02 Desember 2019
Ilham Nur Leksono,

Tommi Alfian Armawan Sandi langsung dengan jaringan komputer yang ada.

\section{TINJAUAN PUSTAKA}

Dalam melakukan penelitian ini ada beberapa tinjauan studi yang dilakukan, yaitu

\subsection{Topologi}

Menurut Madcoms [8] Jaringan komputer (computer network) dapat diartikan sebagai sekelompok komputer yang dihubungkan menggunakan media tertentu sehingga antara komputer dapat saling berhubungan untuk berbagi data, informasi, program aplikasi, dan perangkat keras, seperti printer, scanner, CD/DVD Driver, ataupun hardisk.

Pada dasarnya jaringan komputer dapat dibedakan luas area yang dapat dijangkau oleh jaringan itu sendiri. Hal ini berarti luas area dapat ditentukan berdasarkan jarak atau jangkauan dari jaringan itu sendiri menurut Madcoms [9].

Local Area Network adalah jaringan yang dibatasi oleh area yang relative kecil. Jaringan jenis ini biasanya menghubungkan antar-komputer satu dengan lainnya atau bisa juga node satu dengan node lainnya. Daerah jangkauan LAN tidaklah terlalu jauh, missal dalam suatu ruangan atau satu area dengan radius antara $100 \mathrm{~m}$ sampai $2.000 \mathrm{~m}[10]$, tergantung dari jenis kabel yang digunakan. Jaringan local tidak terlalu sulit dalam perawatannya, dikarenakan terminal yang digunakan. Jaringan local tidak terlalu sulit dalam perawatannya, dikarenakan terminal yang digunakan belum terlalu banyak, serta cakupan area yang masih kecil, sehingga seorang teknisi jaringan tidak akan mengalami banyak kesulitan dalam memperbaiki serta merawat jaringannya.

Menurut Madcoms [9] Router merupakan yang lebih canggih dibandingkan dengan switch. Sebuah router terdiri atas hardware dan software (memiliki sistem operasi sendiri) untuk mengatur rute data dari asal sumber ke tujuan. Router memiliki sistem operasi canggih yang memungkinkan kita untuk mengkonfigurasi port-port koneksinya. Kita dapat melakukan paket data dari berbagai protokol jaringan yang berbeda, seperti TCP/IP, IPX/SPX dan Apple Talk. Router juga membagi LAN ke dalam segmen-segmen yang sudah memiliki traffic data yang besar dan jenuh. Router juga dapat menghubungkan jaringanjaringan teknologi WAN yang berlainan[11]. Kadang router juga memiliki fungsi sebagai hub, access point sekaligus repeater.

\subsection{Penelitian Terdahulu}

Penelitian yang sebelumnya dilakukan dengan melakukan optimalisasi jaringan dengan teknik load balance permasalahan yang dihadapi adalah jaringan yang tidak berjalan dengan semestinya dan tidak ada manajemen backup internet supaya internet yang mengarah ke user berjalan lancar [12]. Pada penelitian kedua untuk langkah optimasi proses analisis, penelitian ini menggunakan metode FIFO (First In First Out), PCQ (PerConnection Queue), SFQ (Stochastic Fairness Queue) dan RED (Random Early Drop) yang akan diterapkan pada mikrotik RB1100. Metode FIFO, PCQ, SFQ dan RED merupakan metode dari Simple Queue yang dapat dipergunakan dalam penyettingan mikrotik. Dalam proses analisis penelitian ini, akan dilakukan penyetinggan pada mikrotik dengan menggunakan metode FIFO, PCQ, SFQ dan RED. Untuk penyetingan mikrotik dapat dilakukan menggunakan aplikasi winbox. Pada setiap metode yang diterapkan, akan di analisis dengan menggunakan aplikasi wireshark. Hasil analisis dari keempat meode akan dibandingan dengan pembobotan berdasarkan standar TIPHON. Semakin besar nilai yang didapat berdasarkan standar TIPHON, semakin baik 
kualitas jaringan internet yang dihasilkan [13]. Dan penelitian yang dilakukan untuk optimasi jaringan wireless dengan router mikrotik pada studi kasus kampus BSI tanggerang, permasalahan yang dihadapi adalah tidak ada jaringan yang dapat di gunakan secara mobile dan belum ada manajemen limitasi bandwidth dan hak askes suatu situs.[14]

Dari penelitian yang dilakukan sebelumnya dapat disimpulkan bahwa untuk optimalisasi suatu jaringan perlu beberapa metode yang digunakan dan melihat keadaan dilapangan supaya jaringan yang dibuat dapat berjalan dengan optimal.

\section{METODOLOGI PENELITIAN}

Dalam memperoleh data melakukan riset secara langsung dengan menggunakan prosedur yang ada sehingga data-data yang didapatkan akurat dan benar. menggunakan metode ini sebagai sarana pengambilan data terkait jaringan komputer yang ada, dimana metode ini merupakan hasil peninjauan serta penelitian langsung dari objek yang diamati pada Robotic Laboratory Bogor. Analisa dilakukan secara satu minggu untuk melihat bagaimana cara kerja jaringan tersebut dari ISP sampai ke setiap pengguna yang ada. Metode ini lakukan dengan bantuan dan arahan dari pembimbing serta staf yang bertugas guna mendapatkan informasi dan data terkait objek yang diteliti serta guna menambah wawasan keilmuan yang terkait dengan observasi yang dilakukan menggunakan analisa penelitian sebagai berikut:

\section{a. Analisa}

Kebutuhan komunikasi di sebuah instansi sangatlah penting. Rancangan jaringan komputer berbasis MikroTik Router ini memungkinkan agar jaringan yang ada bisa terhubung dan berkomunikasi dengan lebih baik. Dari sisi hardware perlu diadakan penambahan komputer yang bertugas sebagai server, MikroTik router dan kabel jaringan.

b. Desain

Desain dari perancangan jaringan komputer yang akan di usulkan pada Robotic Laboratory Bogor menggunakan topologi tree.

c. Implementasi

Membuat dan mengajukan proposal pembangunan jaringan komputer berbasis MikroTik router tersebut kepada Manajer Robotic Laboratory Bogor yang sebelumnya telah dilakukan observasi, menginformasikan hal-hal penting yang berguna untuk kemajuan jaringan komputer yang ada pada instansi.

d. Uji Coba

Rancangan yang di ajukan akan disimulasikan menggunakan routerboard dan software winbox.

Metode penelitian merupakan suatu cara bagaimana seorang dapat memahami suatu pembahasan, permasalahan, dan pemecahan masalah didalam sebuah jaringan komputer berbasis MikroTik pada instansi tersebut.

\section{HASIL DAN PEMBAHASAN}

Konsep jaringan usulan pada Robotic Laboratory Bogor adalah dengan menambahkan beberapa perangkat dan konfigurasu pada jaringan komputer yang sudah ada dan berjalan, sehingga jaringan komputer yang ada bisa lebih optimal dan terstruktur. Perangkat yang ditambahkan berupa MikroTik router yang akan menjadi pusat manajemen pada jaringan komputer yang ada pada Robotic Laboratory Bogor dan beberapa kabel tambahan untuk menghubungkan antara modem, MikroTik router, dan switch. Sedangkan untuk konfigurasi yang akan ditambahkan pada jaringan komputer berjalan meliputi, $D H C P$ Client, DHCP Server, Manajemen Bandwidth, konfigurasi web proxy, hotspot, dan firewall.

Dengan memanfaatkan MikroTik router serta konfigurasinya, diharapkan jaringan komputer yang ada bisa lebih 
Jusikom : Jurnal Sistem Komputer Musirawas Vol 04 No 02 Desember 2019
Ilham Nur Leksono,

Tommi Alfian Armawan Sandi optimal dan lebih aman digunakan untuk membantu pekerjaan komputerisasi pada kantor Robotic Laboratory Bogor.

Setelah dilakukan riset pada jaringan komputer yang ada pada Robotic Laboratory Bogor, masih belum adanya perangkat administrasi jaringan seperti MikroTik router, maka diajukannya optimalisasi jaringan komputer yang ada dengan menambahkan beberapa perangkat yang bertugas sebagai admin jaringan dan sebagai penyebar jaringan internet yang telah ada.

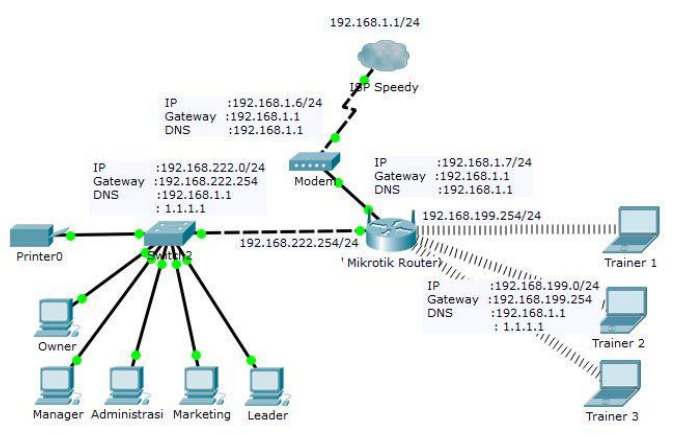

Gambar 1. Skema Jaringan Usulan

Sumber internet pada skema jaringan usulan adalah menggunakan ISP dimana masing-masing komputer memiliki IP Address yang didapat dari ISP yang telah melewati MikroTik router terlebih dahulu sebagai pusat manajemen jaringan komputer, dalam hal ini menggunakan konfigurasi DHCP Client MikroTik router dan DHCP Server sebagai penyebar IP Address melalui kabel ataupun nirkabel. pada skema diatas modem router telah dialihfungsikan hanya sebagai modem, fungsi router di gantikan oleh MikroTik router yang sekarang telah menjadi pusat manajemen jaringan komputer yang ada, dan pada konektivitas ditambahkan manajemen bandwidth dan konfigurasi hotspot agar komputer selain komputer yang ada pada Robotic Laboratory Bogor tidak bisa sembarang terhubung ke jaringan yang ada, serta pembagian bandwidth yang disesuaikan dengan kebutuhan pada setiap klien yang ada. Kemudian adanya konfigurasi web proxy sebagai pengatur jaringan sehingga komputer yang terhubung dengan jaringan bisa lebih aman saat digunakan serta dimaksimalkan fungsinya dalam memenuhi pekerjaan komputerisasi yang ada pada Robotic Laboratory Bogor.

Topologi yang diusulkan merupakan pengembangan dari topologi yang ada sebelumnya karena terdapat beberapa penambahan konfigurasi jaringan. Untuk perancangan wide area network tidak terlalu banyak perubahan, dalam hal ini masih menggunakan topologi yang sudah ada yaitu topologi tree.

Dilihat pada jaringan komputer yang ada pada Robotic Laboratory Bogor, masih belum adanya perangkat administrasi jaringan seperti MikroTik router, maka diajukannya optimalisasi jaringan komputer yang ada dengan menambahkan beberapa perangkat yang bertugas sebagai admin jaringan dan sebagai penyebar jaringan internet yang telah ada, Sistem keamanan pada jaringan komputer Robotic Laboratory Bogor tidak ada tambahan atau usulan karena hanya fokus untuk membahas usulan penambahan perangkat dan konfigurasi agar jaringan komputer yang sudah ada bisa lebih optimal,

A. Rancangan Aplikasi

Untuk melakukan konfigurasi $D H C P$ pada jaringan ada dua langkah yang harus dilakukan, yang pertamaadalah konfigurasi DHCP client, agar MikroTik router mendapatkan IP dari ISP dan terhubung dengan internet, kemudian konfigurasi DHCP server, agar klien mendapatkan IP dan dapat mengakses internet.

Berikut adalah konfigurasi $D H C P$ client, agar MikroTik router mendapatkan IP langsung dari modem ISP, untuk melakukan konfigurasi DHCP client pada MikroTik router, harus menyiapkan terlebih dahulu interface atau port mana yang akan digunakan sebagai port $D H C P$ client, pada MikroTik router biasanya digunakan pada port 1. Kemudian masuk ke menu $D H C P$ client dan buat baru, dengan menggunakan interface ether 1, Add Default Route=yes, dan ceklis pada Use Peer DNS serta Use Peer NTP. Setelah itu pastikan status DHCP client yang telah dibuat menjadi "bound" dan mendapatkan IP Address dari ISP. 
Jusikom : Jurnal Sistem Komputer Musirawas Vol 04 No 02 Desember 2019
Ilham Nur Leksono,

Tommi Alfian Armawan Sandi

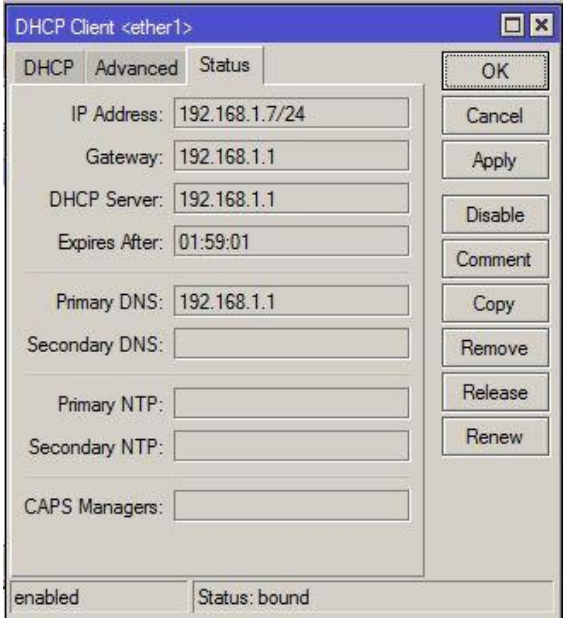

Gambar 2. Status MikroTik router setelah mendapat IP dari ISP

Pada tahap ini MikroTik router sudah terhubung dengan internet, tetapi hanya MikroTik routernya saja, sedangkan untuk komputer klien perlu menambahkan konfigurasu DHCP server agar komputer klien mendapatkan IP address dan terhubung ke jaringan yang ada. Port yang digunakan untuk konfigurasi $D H C P$ server adalah port 2. Sebelum mulai mengkonfigurasu, pastikan port 2 atau ether2 sudah diberikan IP address terlebih dahulu, agar komputer klien mendapatkan IP address sesuai dengan konfigurasu yang telah dibuat. Pilih menu IP, kemudian pilih pada DHCP Server, lalu DHCP Setup. Pilih interface yang akan kita gunakan sebegai DHCP Server, yaitu ether2, dan pastikan IP address sesuai dengan IP ether2 beserta dengan netmasknya. Kemudian untuk gatewaynya menggunakan IP address pada ether2 yang sebelumnya telah diberikan secara manual.

Sedangkan untuk Address to Give Out dieseuaikan dengan kebutuhan yang ada pada Robotic Laboratory Bogor. Lalu selanjutnya adalah menentukan DNS untuk klien, secara otomatis DNS Server akan mengambil informasi setting pada tabel DNS, yang sebelumnya telah dikonfigurasi bersamaan dengan $\mathrm{DHCP}$ Client, atau bisa juga ditambahkan DNS lain secara manual, dan langkah terakhir adalah menentukan Lease-Time, yaitu berapa lama waktu sebuah IP address akan dipinjamkan ke klien. Untuk menghindari penuh/kehabisan IP address, setting Lease-Time jangan terlalu lama, misalkan 1 hari saja (1d 00:00:00). Sampai pada langkah ini $D H C P$ Server telah selesai di konfigurasi.

Hal yang kemudian harus dilakukan adalah menyambungkan switch ke port 2 yang telah dikonfigurasi tadi dan dilanjutkan dengan menyambungkan komputer klien ke switch tersebut. Lalu ubang pengaturan IP pada komputer klien menjadi otomatis atau "Obtain an IP Address Automatically", dan pastikan status jaringan pada komputer klien menjadi DHCP enabled =yes dan IP yang didapat sesuai dengan konfigurasi yang telah dilakukan pada MikroTik router.

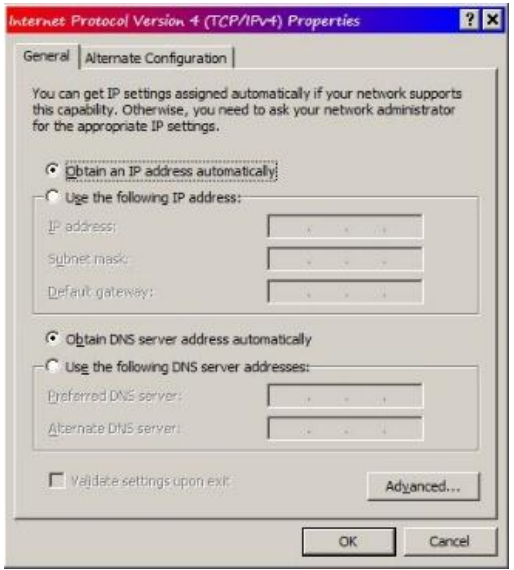

Gambar 3. Konfgurasi request DHCP dari klien

Setelah jaringan kabel dikonfigrashi, selanjutnya adalah melakukan penambahan berupa jaringan nirkabel untuk digunakan beberapa klien. Untuk memulai konfigurasi jaringan nirkabel, pastikan interface yang digunakan yaitu wlan 1 sudah diberikan $I P$ address sebelumnya secara manual, dan telah ditambahkan konfigurasu $D H C P$ Server pada interface wlan1. Untuk konfigurasu DHCP server pada wlan1, langahnya sama seperti konfigurasu $D H C P$ server di ether2, hanya saja untuk IP, dan gatewaynya yang berbeda.

Pada konfigurasi wireless ini bertujuan agar klien bisa terhubung dengan jaringan secara fleksibel dan mobile tanpa harus terkendala panjang-pendek dari jaringan kabel. Selanjutnya adalah setting wireless interface. Pada menu Wireless, 
Jusikom : Jurnal Sistem Komputer Musirawas Vol 04 No 02 Desember 2019
Ilham Nur Leksono,

Tommi Alfian Armawan Sandi pilihlah tab Interface kemudia double-click pada wlan1. Setting wlan1 pada AP-Bridge, masukan ssid "wifi@Roboratory", band $2 \mathrm{GHz}-\mathrm{B} / \mathrm{G} / \mathrm{N}$, serta frekuensi yang akan digunakan. Kemudian untuk security profile, sebelumnya harus dibuat pada menu wireless dan tab Security Profiles. Tambahkan security profile yang baru, isi nama profil "Roboratory3" dengan mode dynamic keys, ceklis semua mode pada Authentiation Types, Unicast Ciphers, dan Group Ciphers. Kemudian pada kolom PreShared key isi dengan "connect, now!", lalu klik Ok.

Setelah menambahkan security profile, kembali pada tab interfaces dan ubah security profile dari default menjadi Roboratory, security profile ini berfungsi sebagai keamanan atau password untuk bisa terhubung ke jaringan wireless yang telah dibuat untuk kantor Robotic Laboratory Bogor. Selanjutnya adalah menghubungkan klien pada jaringan wireless yang sudah dibuat sebelumnya, sesuai dengan ssid dan password yang telah dikonfigurasi.

a) Manajemen Jaringan

Manajemen jaringan menjadi sangat oenting dalam membangun suatu jaringan kompyter apalagi jika jarigan sudah sangat luas cangkupannya. Agar proses komunikasi antar perangkat serta anatara Client-Server dan menjaga jaringan tetap berjalan dengan baik dan terkontrol. Manajemen pertama yang akan dikonfigurasi adalah membuat hotspot login untuk jaringan nirkabel, unuk konfigurasinya menggunakan port wlan1. Pada hotspot ini akan ada 3 user login yang digunakan, yaitu trainer001, trainer002, dan trainer003.

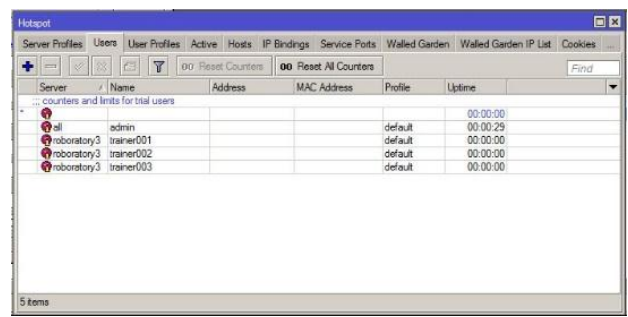

Gambar 4. Konfigurasi user IP Hotspot
Setelah sudah membuat user, klien yang sudah terhubung bisa langsung terkoneksi internet dengan melakukan login user dahulu pada halaman roboratory3.MikroTik.com. Manajemen yang kedua adalah manajemen bandwidth. Pada konfigurasi ini, jaringan yang ada akan dibatasi dalam penggunaan bandwidthnya agar lebih optimal dan efisien digunakan oleh klien. Pada winbox, pilih menu Queue, kemudian beri nama konfigurasi bandwidth dan pilih port mana yang akan menjadi taget dari manajemen bandwidth. Setelah itu berikan max-upload $=1 \mathrm{M}$ dan maxdownload $=512 \mathrm{k}$, kemudian klik Ok.

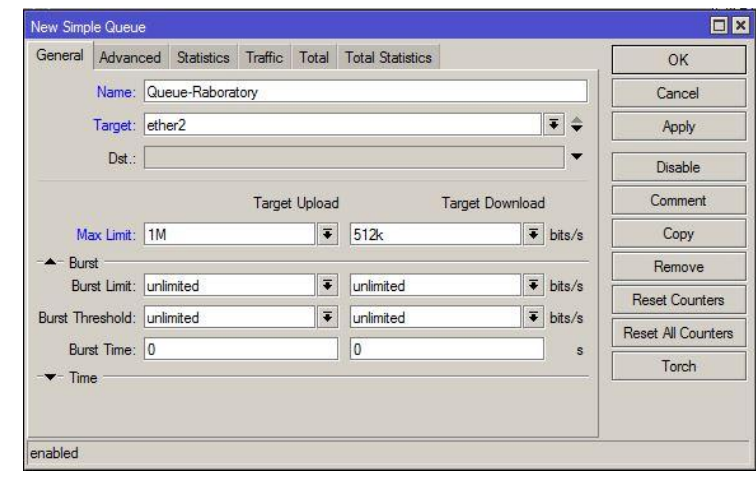

Gambar 5. Konfigurasi manajemen bandwidth dengan simple queue

Dan manajemen terakhir yang akan di konfigurasi adalah web proxy. Pada proxy ini akan dilakukannya pemblokiran beberapa situs dan kata kunci yang sensitif serta berkonten negatif.

Sebelum mulai mengkonfigurasi web proxy, agar tidak perlu melakukan setting pada klien satu persatu, ubah web proxy menjadi Transparent Proxy, dengan membuat NAT Rules tambahan yang berada pada menu IP firewall, kemudian pilih tab NAT. Kemudian isi konfigurasi menjadi, chain $=$ dstnat, protocol $=6$ (tcp), dst-port $=80$, in-interface $=$ ether 2 . Lalu ubah tab action menjadi, action=redirect, to ports $=8080$ lalu klik Ok. 
Jusikom : Jurnal Sistem Komputer Musirawas Vol 04 No 02 Desember 2019
Ilham Nur Leksono,

Tommi Alfian Armawan Sandi

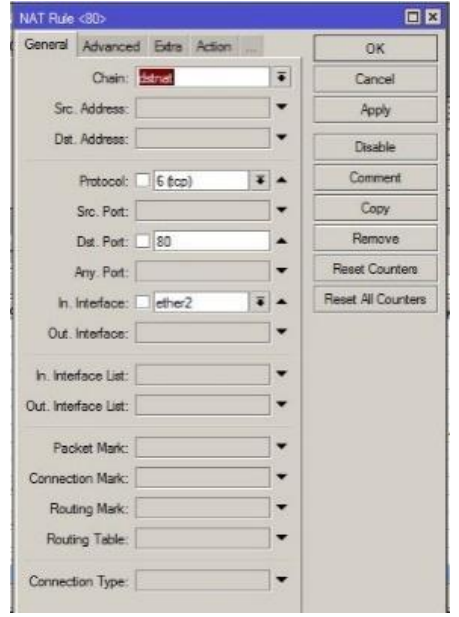

Gambar 6. Menambahkan NAT rules baru

Setelah menambahkan NAT rules, selanjutnya adalah mengkonfigurasi web proxy dan menambahkan daftar situs yang akan di blok. Pada menu IP pilih Web Proxy, kemudian ceklis Enabled dan isi konfigurasinya menjadi, port $=8080$, cache administrator $=$ WebMaster99, max cache size =unlimited, max cache object size $=2048$.

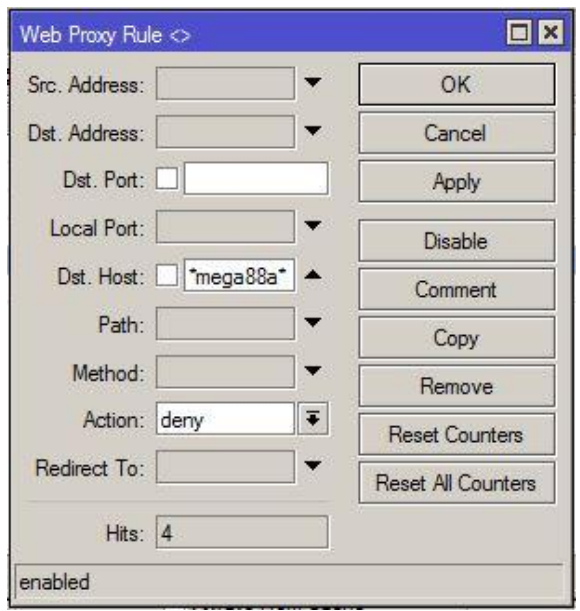

Gambar 7. Konfigurasi Web proxy

Klik Access, dan tambahkan situs yang akan diblok untuk klien sehingga tidak bisa diakses. Tambahkan $d s t$-host atau situs yang akan di blok, action=deny.

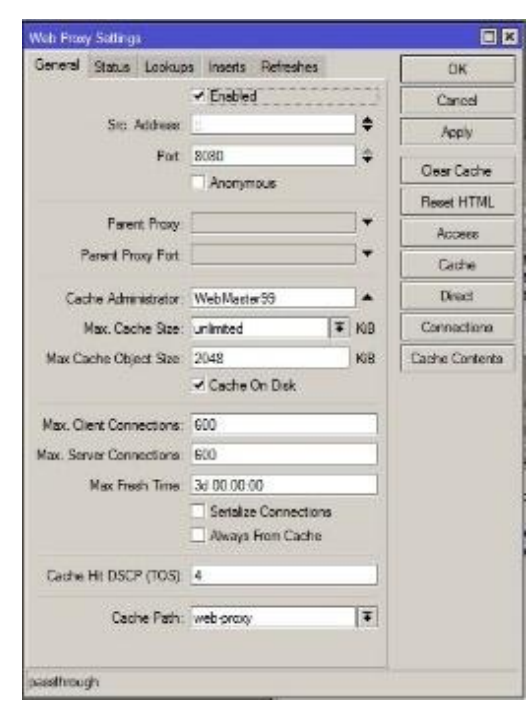

Gambar 8. Menambahkan situs yang akan diblok

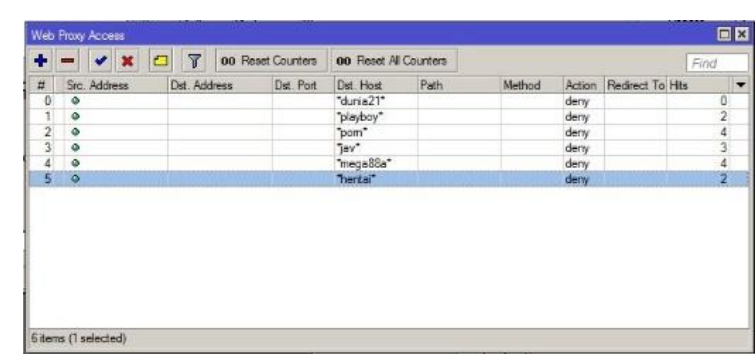

Gambar 9. Daftar situs yang diblok

b) Pengujian Awal

Pada tahap pengujian jaringan awal dilakukan sebelum adanya penerapan konfigurasi tambahan pada router MikroTik dapat dilihat bahwa klien bisa langsung terkoneksi dengan internet tanpa harus login terlebih dahulu, serta kecepatan akses masih belum dibatasi.

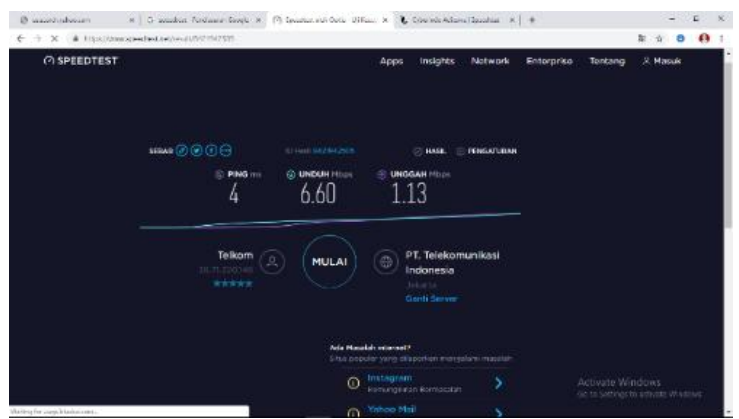

Gambar 10. Uji coba kecepatan akses (sebelum) 
Jusikom : Jurnal Sistem Komputer Musirawas

Vol 04 No 02 Desember 2019
Ilham Nur Leksono,

Tommi Alfian Armawan Sandi melakukan tes untuk mencoba akses ke beberapa situs yang nantinya akan di blok., dapat dilihat bahwa situs youtube.com dan mega88a.com masih bisa di akses secara bebas.

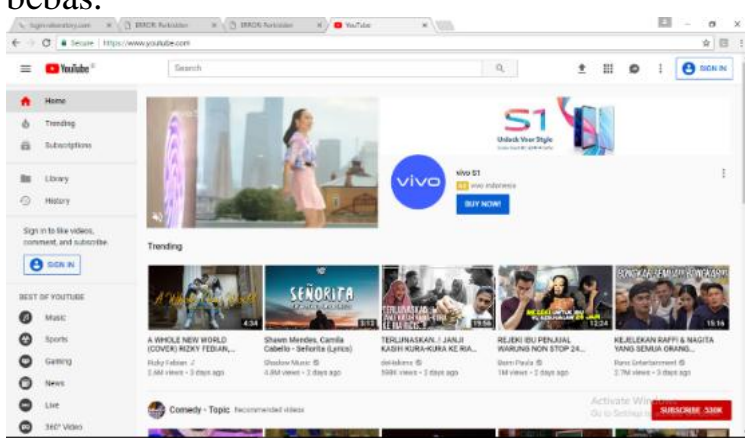

Gambar 11. Uji coba akses situs youtube.com (sebelum)

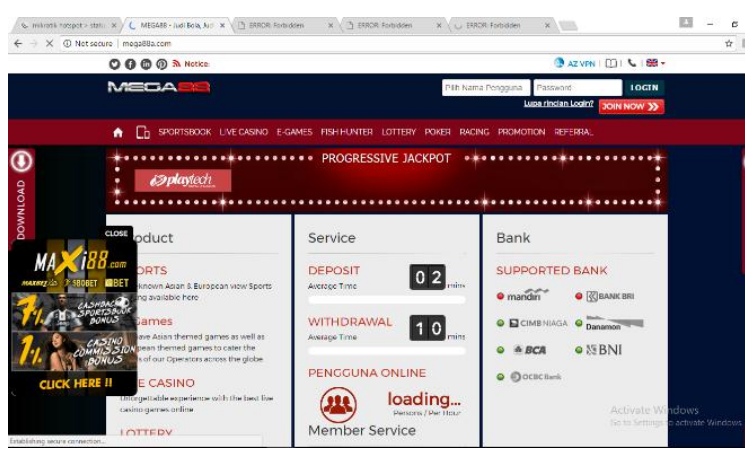

Gambar 12. Uji coba akses situs mega88a.com (sebelum)

c) Pengujian Akhir

Pada tahap pengujian jaringan ini sudah menerapkan konfigurasi hotspot login untuk klien (trainer) pada router MikroTik. melakukan uji coba login ke jaringan MikroTik dengan menggunakan user $=$ trainer001 dan password $=$ robot001, sehingga klien bisa mendapatkan IP dan terkoneksi ke internet.

Welcome trainer001!

\begin{tabular}{|r|l|}
\hline IP address: & 192.168 .199 .19 \\
\hline bytes up/down: & $113 \mathrm{~B} / 78 \mathrm{~B}$ \\
\hline connected: & Os \\
\hline status refresh: & $1 \mathrm{~m}$ \\
\hline
\end{tabular}

$\log$ off

Gambar 13. Status login hotspot MikroTik (sesudah) kemudian melakukan uji coba kecepatan akses yang sebelumnya telah dikonfigurasi menggunakan simple quеие, dapat dilihat kecepatan akses yang telah dibatasi menjadi berubah secara signifikan.

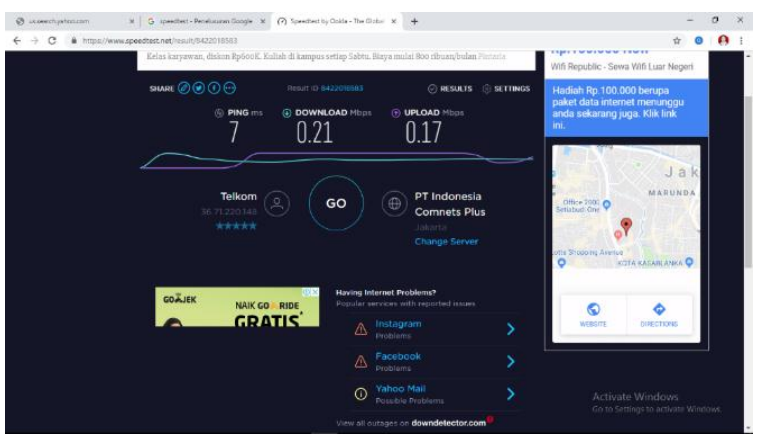

Gambar 14. Uji coba kecepatan akses (sesudah)

Gambar diatas adalah hasil dari konfigurasi limit bandwidth dimana yang sebelumnya bandwidth yang ada tidak dibatasi, max-upload=unlimited, maxdownload=unlimited, dan setelah dibatasi kecepatan aksesnya menjadi berubah secara signifikan, $\quad$ max-upload $=1 \mathrm{M}, \quad$ maxdownload $=512 \mathrm{k}$.

Kemudian untuk jaringan web proxy juga sudah melakukan uji coba mengakses kembali situs yang diblok pada konfigurasi web proxy sebelumnya, dapat dilihat bahwa situs youtube.com dan mega88a.com sudah tidak bisa diakses kembali.

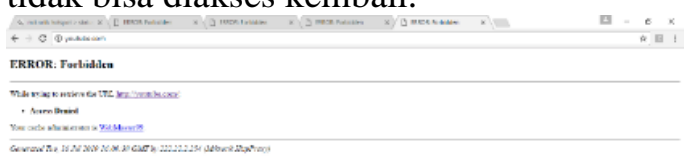

Gambar 15. Uji coba akses situs youtube.com (sesudah)

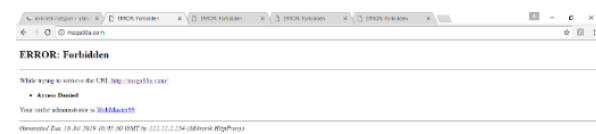


Jusikom : Jurnal Sistem Komputer Musirawas Vol 04 No 02 Desember 2019
Ilham Nur Leksono,

Tommi Alfian Armawan Sandi
Gambar diatas adalah uji coba akses ke situs yang masuk kedalam daftar blok pada web proxy yang telah dikonfigurasi sebelumnya, dimana yang sebelumnya bisa bebas diakses, menjadi tidak bisa diakses dengan status ERROR: Forbidden, Access Denied.

\section{KESIMPULAN}

Dari hasil penelitian dan analisa maka dapat disimpulkan bahwa sistem jaringan komputer yang ada pada Robotic Laboratory Bogor menggunakan topologi star dengan internet yang bersumber dari ISP. Optimalisasi jaringan komputer menggunakan MikroTik router dengan mengaktifkan DHCP Server, manajemen bandwidth, hotspot, firewall, wireless dan web proxy hasil nya jaringan komputer yang ada pada Robotic Laboratory Bogor menjadi lebih optimal dan maksimal dalam penggunaan serta pengawasannya.

\section{SARAN}

Mempelajari dan menganalisa jaringan komputer Robotic Laboratory Cabang 3 Bogor penulis memberikan saransaran sebagai berikut:

1. Penambahan perangkat administrasi jaringan, seperti router mikrotik.

2. Menggunakan proxy eksternal, agar tidak membebankan router mikrotik.

3. Penambahan tenaga ahli berupa IT Support untuk bertanggung jawab penuh atas jaringan komputer yang ada.

4. Melakukan maintanace secara berkala untuk sistem jaringan yang berada di Robotic Laboratory Cabang 3 Bogor.

\section{DAFTAR PUSTAKA}

[1] F. Prasetyo and T. Muhammad, "Rancang Bangun Jaringan Lan Pada PT . Rapigra Cikarang then made solution handling," J. Tek. Komput. AMIK BSI, vol. III, no. 2, pp. 120 126, 2017.

[2] Suryanto, "Pengaturan Pemakaian Bandwidth dan Akses Jaringan Komputer Menggunakan Mikrotik
Router," J. Ilmu Pengetah. Dan Teknol. Komput., vol. 3, no. 2, pp. 167-172, 2018.

[3] Dimarzio, "Konfigurasi Keamanan Jaringan Komputer Pada Router Dengan Metode Acl ' S," Tek. Komput. AMIK BSI, vol. I, no. 2, pp. 152-158, 2015.

[4] T. D. Purwanto, "Analisis Kinerja Dynamic Routing pada Protokol Routing EIGRP untuk Menentukan Jalur Terbaik dengan Diffusing Update Algorithm (DUAL)," JUITA J. Inform., vol. 6, no. 2, p. 89, 2018.

[5] T. Rahman, "Implementasi Interface Virtual Local Area Network Dan Firewall Pada Mikrotik Dan Switch Manajemen," J. Ilmu Pengetah. dan Teknol. Komput., vol. 4, no. 1, pp. 29-36, 2018.

[6] N. Arkaan and D. V. S. Y. Sakti, "Implementasi Low Interaction Honeypot Untuk Analisa Serangan Pada Protokol SSH," J. Nas. Teknol. dan Sist. Inf., vol. 5, no. 2, pp. 112120, 2019.

[7] E. W. Sinuraya and J. K. Sembiring, "Perancangan Jaringan Komputer Di Pt. Dirgantara Indonesia Dengan Teknik Variable Length Subnet Mask (Vlsm) Dan Virtual Local Area Network (Vlan)," vol. 17, no. 3, pp. 157-161, 2015.

[8] MADCOMS, Cepat Dan Mudah Membangun Sistem Jaringan Komputer. Yogyakarta: Andi Publisher, 2013.

[9] MADCOMS, Panduan Lengkap Membangun Sendiri Sistem Jaringan komputer. Yogyakarta: Andi Publisher, 2015.

[10] H. Kuswanto and J. Bastari, "Sniptek 2014 Isbn: 978-602-72850-5-7 Perancangan Jarigan Wide Area Network Pada Pt Jasindo Lintastama Isbn: 978-602-72850-5 -7," Sniptek 2014, pp. 213-218, 2014.

[11] M. Haqqi and M. Badrul, "Segmentasi Jaringan Dengan Menggunakan Virtual Local Area Network (Study Kasus Pt. Jalur Nugraha Ekakurir)," Tek. Komput. AMIK BSI, vol. II No.2, no. 2, p. 8, 
2016.

[12] 1Muhammad Dedy Haryanto and I. Riadi, "ANALISIS DAN OPTIMALISASI JARINGAN MENGGUNAKAN TEKNIK LOAD BALANCING (Studi Kasus : Jaringan UAD Kampus 3)," J. Sarj. Tek. Inform., vol. 2, pp. 1370-1378, 2014.

[13] T. Pratama, M. A. Irwansyah, and Yulianti, "Perbandingan Metode PCQ, SFQ, RED Dan FIFO Pada Mikrotik Sebagai Upaya Optimalisasi Layanan Jaringan Pada Fakultas Teknik Universitas Tanjungpura," J. Tek. Inform. Univ. Tanjungpura, vol. 3, no. 3, pp. 298303, 2015.

[14] F. Doni, "Optimalisasi Jaringan Wireless Dengan Router Mikrotik Studi Kasus Kampus Bsi Tangerang," Evolusi, vol. 2, no. 1, pp. 37-45, 2015. 